\title{
Development of an Optimal Design Software for Conveyors based on the Discrete Element Method
}

\author{
Xuejiao Wang ${ }^{1, \mathrm{a}}$,Fu Hong ${ }^{1}$, Lina Dang ${ }^{1}$, Jianqun $\mathrm{Yu}^{2, \mathrm{~b}}$ \\ ${ }^{1}$ College of Computer Science and Technology, Jilin University, \\ Changchun 130012, China \\ ${ }^{2}$ School of Biological and Agricultural Engineering, Jilin University, \\ Changchun 130022,China \\ a email: E-mail: fuhong@jlu.edu.cn, \\ bemail: E-mail: yujianqun@jlu.edu.cn
}

\begin{abstract}
.
Because of the complexity of conveyors working process, so far the research and the design of conveyors usually rely on the designer's experience or test methods. In order to help mechanical engineers identify problems and modify the design at the design conveyor stage by showing the work process and job performance of the conveyor .Basing on the discrete element methods, this paper design and implement the working process of conveyors and conveyor performance analysis software. And achieve integration with the three-dimensional CAD software.This software can simulate conveyors working process in a short period of time and make conveyor achieve higher transport efficiency, to provide a new method and tools for research and design of the conveyor.
\end{abstract}

Keywords: Discrete element method; Granular materials; Conveyors; Computer Aided Design; Optimal design

\section{Introduction}

Currently, Conveyors are widely used in agriculture, mining, coal mining and other industries [1]. If conveyor damage occurs in the course of work, it will result in the loss of 5 million per kilometer long of the conveyor and production 
halt with significant economic losses, and even casualties with its serious consequences. So people are very concerned about the performance of the conveyor. But because of conveyor materials, work environment and complexity of working process ,so far research and design of conveyors mostly rely on the designer's experience or test methods. This means that the only way to test the conveyor performance is to put them into use. So it is difficult to achieve the pre-designed indicators [2]. Currently there has been foreign commodity conveyor simulation software. But because of the expensive price and the possibility of being banned due to conflict, The research of conveyor performance analysis software with the simulation of granular materials is necessary.

\section{Theory}

\section{Particle modeling approach}

Most materials conveyed by conveyors are particulate materials, which can be divided into spherical particles and non-spherical particles. Spherical or approximately spherical particles use ball equation $\frac{x^{2}}{a}+\frac{y^{2}}{b}+\frac{z^{2}}{c}=1$ to establish particle analysis model[3]. This paper selects soybeans as particulate materials, $96 \%$ of which are approximately sphericals.

\section{Discrete element calculation method on conveyor working process}

\section{The calculation of Contact overlaps and contact forces}

The contact forces are divided into forces between particles and particles and forces between particles and boundaries. When using the linear viscoelastic model, the contact force is synthesized by the Normal direction and tangential direction force. The normal direction contact force [4]

$$
F_{\mathrm{X}}^{(\mathrm{t})}=F_{X K}^{(t)}+F_{X D}^{(t)}
$$


$F_{X}^{(t)}$ is the normal direction force of $t$ moment between two objects; $F_{X K}^{(t)}$ is the elastic force in the normal direction. $F_{X K}^{(t)}=-K_{X} \delta_{X}, K_{X}$ is the stiffness coefficient in the normal direction. $\delta_{X}$ is the contact overlap in the normal direction(As shown in Fig.1, Fig. 2). $F_{X D}^{(t)}$ is the damping force in the normal direction, $F_{X D}^{(t)}=-C_{X} \Delta \mathrm{u}_{\mathrm{X}} / \Delta \mathrm{t} . \mathrm{C}_{\mathrm{X}}$ is the viscous damping coefficient in the normal direction. $\Delta u_{\mathrm{x}}$ is the relative displacement in the normal direction at the two-object contact points. $\Delta t$ is the calculation time step. The tangential force [5]

$F_{Y(Z)}^{(t)}=F_{Y(Z) K}^{(t)}+F_{Y(Z) D}^{(t)}$

$F_{Y(Z)}^{(t)}$ is the tangential direction force of $t$ moment between two objects. $F_{Y(Z) K}^{(t)}$ is the elastic force in the tangential direction. $F_{Y(Z) K}^{(t)}=F_{Y(Z) K}^{(t-\Delta t)}+\Delta F_{Y(Z) K}^{(t)} \cdot F_{Y(Z) K}^{(t-\Delta t)}$ is the elastic force in the tangential direction in last calculation time step. $\Delta F_{Y(Z) e}^{(t)}=-K_{Y(Z)} \Delta u_{Y(Z)} \cdot K_{Y(Z)}$ is the stiffness coefficient in the tangential direction. $\Delta u_{Y(Z)}$ is relative displacement in the tangential direction. $F_{Y(Z) D}^{(t)}$ is the damping force in the tangential direction between two objects, $F_{Y(Z) D}^{(t)}=-C_{Y(Z)} \Delta u_{Y(Z)} / \Delta t . C_{Y(Z)}$ is viscous damping coefficient in the tangential direction. 


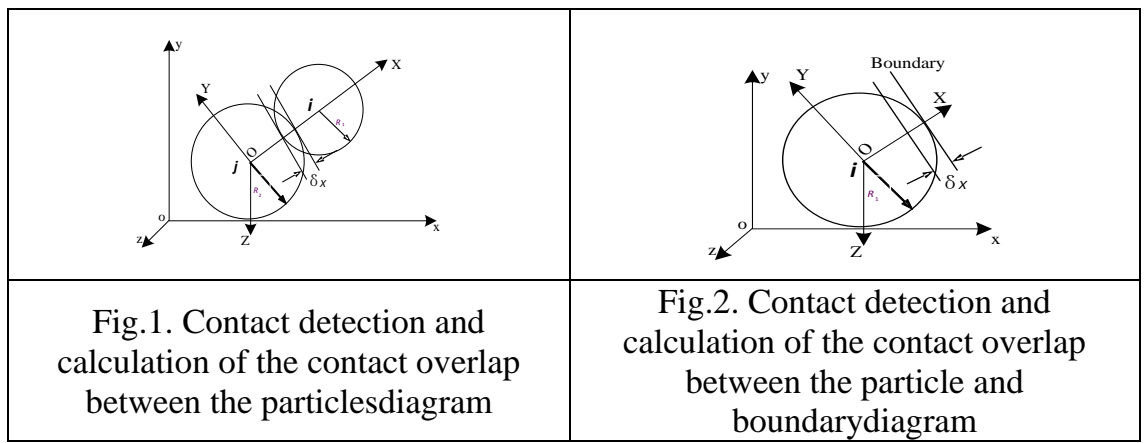

\section{Software Development}

\section{Software structures and processes}

This paper developed conveyor working process simulation and performance analysis software, based on the above models and methods by VS development tools, in the WINDOWS environment. The Software consists of four subsystems, CAD design subsystem, conveyor discrete element analysis modeling subsystem, discrete element method analysis of iterative calculations subsystem and conveyor performance analysis subsystem. CAD design subsystem consists of software components and mechanical designer which can design a three-dimensional CAD model of the conveyor. Conveyor discrete element analysis modeling subsystem is a secondary development of CAD software. This subsystem completes the analysis modeling conveyor by extracting conveyor elements which are contacted with granular material and by adding motion properties and material properties. Discrete element method analysis of iterative calculations subsystem is responsible for calculating the contact situation, particles interactions and particles movement. Conveyor performance analysis subsystem visualizes the results files and provides the force field related with particles, the particle velocity field, the particles flow and conveyor working resistance after the calculation to evaluate the performance of the conveyor. 


\section{Examples of software validation}

To verify the correctness and validity of the discrete element method simulation of conveyor , two-level rollers conveyor model is used to implement working process simulation analysis of the conveyor using the discrete element method, the input parameters is shown in Table 1, the simulation process is shown in Fig.3. Fig. 3(a) shows the particles fall onto the conveyor belt. Fig.3 (b) shows the movement of particles on the conveyor belt, Fig.3 (c) and Fig.3 (d) show stability of the particle movement on the conveyor belt. It can be seen from figures and analysis that the software can achieve the intended function.

Table 1: the input parameters

\begin{tabular}{|c|c|c|}
\hline Parameter & Particles and particles & Particles and boundary \\
\hline $\begin{array}{l}\text { the stiffness coefficient in the normal } \\
\text { direction }(\mathrm{N} / \mathrm{Kg})\end{array}$ & 650 & 1300 \\
\hline $\begin{array}{l}\text { the stiffness coefficient in the } \\
\text { tangential direction }(\mathrm{N} / \mathrm{Kg})\end{array}$ & 440 & 870 \\
\hline $\begin{array}{l}\text { the viscous damping coefficient in the } \\
\text { normal direction }(\mathrm{Ns} / \mathrm{m})\end{array}$ & 0.09 & 0.15 \\
\hline $\begin{array}{l}\text { viscous damping coefficient in the } \\
\text { tangential direction }(\mathrm{Ns} / \mathrm{m})\end{array}$ & 0.07 & 0.12 \\
\hline Static friction coefficient & 0.27 & 0.15 \\
\hline Coefficient of sliding friction & 0.23 & 0.12 \\
\hline Rolling friction coefficient & 0.15 & 0.15 \\
\hline Particle density $\left(\mathrm{Kg} / \mathrm{m}^{3}\right)$ & \multirow{2}{*}{\multicolumn{2}{|c|}{$\begin{array}{c}1209 \\
12000\end{array}$}} \\
\hline The number of particles & & \\
\hline Particle radius(mm) distribution & \multicolumn{2}{|r|}{$\begin{array}{l}12000 \\
\text { By a normal distribution }\end{array}$} \\
\hline $\begin{array}{l}\text { Simulation of mechanical parts } \\
\text { working time (s) }\end{array}$ & \multicolumn{2}{|r|}{20} \\
\hline calculation time step (s) & \multicolumn{2}{|r|}{$5 \times 10^{-5}$} \\
\hline The results save time interval & \multicolumn{2}{|r|}{100} \\
\hline the number of CPU cores & \multicolumn{2}{|r|}{8} \\
\hline
\end{tabular}




\begin{tabular}{|c|c|c|c|}
\hline & & & \\
\hline $\begin{array}{c}\text { (a)Particle generation } \\
\text { and falls on the } \\
\text { conveyor belt }\end{array}$ & $\begin{array}{c}\text { (b) the movement of } \\
\text { particles on the } \\
\text { conveyor belt }\end{array}$ & $\begin{array}{c}\text { (c) stability of the } \\
\text { particle movement on the } \\
\text { conveyor belt }\end{array}$ & $\begin{array}{c}\text { (d) stability of the } \\
\text { particle movement on the } \\
\text { conveyor belt to the } \\
\text { other end }\end{array}$ \\
\hline \multicolumn{2}{|c|}{ Fig.3. working process simulation the discrete element method analysis model of two-level rollers } \\
conveyor
\end{tabular}

Fig.4 is the simulation of the analysis model. Material particles fall to the bottom of the conveyor after generating as shown in Fig.4 (a). The material particles covered the bottom of the conveyor with smooth movement as shown in Fig.4(b).Bucket of the elevator is digging material as shown in Fig.4 (c). bucket of the elevator is dumping as shown in Fig.4 (d). From the simulation and analysis ,it is known that conveyor models can transport materials in accordance with the actual.

Simulation time of the two kind of conveyors is shown in Table 2,according to different number of particles. Through observation and analysis it shows that particles motion through conveyor is similar with the actual situation. Thus the feasibility and effectiveness of the developed software is proved. Users can change the conveyor CAD model and the software can complete the working process simulation analysis of conveyors in different principle and structure, and can analyze and evaluate the performance. Thus the software achieves the goal of optimizing the structure and size parameters of the conveyor in the design stage.

Table2:Simulation time of conveyor

\begin{tabular}{ccccc}
\hline $\begin{array}{c}\text { The number of } \\
\text { material particles }\end{array}$ & 1000 & 5000 & 10000 & 50000 \\
\hline $\begin{array}{c}\text { Simulation time } \\
\text { two-level rollers } \\
\text { conveyor actual } \\
\text { simulation time } \\
\text { bucket elevator }\end{array}$ & $12 \mathrm{~s}$ & $12 \mathrm{~s}$ & $12 \mathrm{~s}$ & $12 \mathrm{~s}$ \\
$\begin{array}{c}\text { actual simulation } \\
\text { time }\end{array}$ & $20 \mathrm{~min}$ & $56 \mathrm{~min}$ & $\begin{array}{c}2 \mathrm{~h} \\
24 \mathrm{~min}\end{array}$ & $\begin{array}{c}13 \mathrm{~h} \\
32 \mathrm{~min}\end{array}$ \\
& & $30 \mathrm{~min}$ & $\begin{array}{c}3 \mathrm{~h} \\
42 \mathrm{~min}\end{array}$ & $\begin{array}{c}17 \mathrm{~h} \\
21 \mathrm{~min}\end{array}$ \\
\hline
\end{tabular}




\section{Conclusions}

Based on in-depth study of discrete element method, this paper developed the conveyor operation and performance analysis software which achieved the integration of the three-dimensional CAD software and the function with design and analysis capabilities. the feasibility and effectiveness of the software have been preliminarily verified by examples. In the actual design process of the conveyor, mechanical designers can use this software to change the conveyor CAD model, to put material particles into the conveyor to get work process and performance analysis of conveyors in different structures in order to identify problems and modify the mechanical design in time.

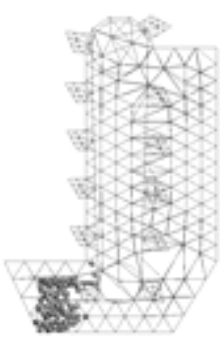

(a) Material particles fall to the bottom of the conveyor after generating

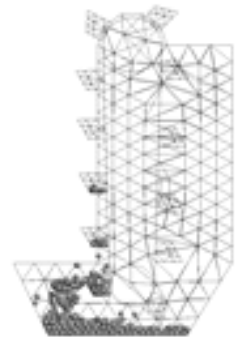

(b) The material particles covered the bottom of the conveyor with smooth movement

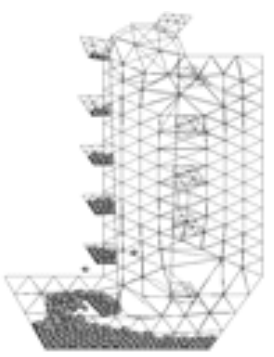

(c) Bucket of the elevator is digging material

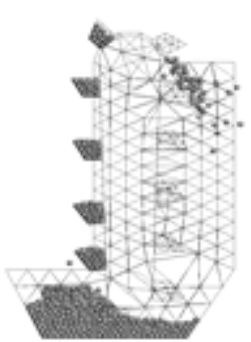

(d) bucket of the elevator is dumping

Fig.4. working process simulation the discrete element method analysis model of bucket elevator

\section{References}

[1] HU Kun.Research on key technologies and application of belt conveyor green design[D].Huainan,AnHui University of Science and Technology,2012."In Chinese"

[2] Hastie D B, Wypych P W. Experimental validation of particle flow through conveyor transfer hoods via continuum and discrete element methods[J]. 
Mechanics of Materials, 2010, 42: 383 394.

[3] Džiugys A, Peters B. An approach to simulate the motion of spherical and non-spherical fuel particles in combustion chambers[J]. Granular Matter, 2001, 3: 231 265.

[4] LI ZhiYong.Basic Theories and Research of Algorithms for DEM Based on Ellipsoidal particals Model[D].Changchun,JiLin University,2008. "In Chinese" [5] Zhu H P,Zhou Z Y,Yang R Y,et al.Discrete particle simulation of particulate systems:Theoretical developments[J].Chemical Engineering Science, 2007,62:3378 3396. 